\title{
PRACTICE OF DOCUMENTATION AT CASUALTY OF TERTIARY CARE HOSPITAL - AN INTERVENTIONAL STUDY
}

\author{
Ramasamy R. ${ }^{1}$, Ganesh Rajendiran ${ }^{2}$, Kagne R.N. ${ }^{3}$ \\ ${ }^{1}$ Assistant Professor, Department of Forensic Medicine \& Toxicology, TMCH, Chennai, ${ }^{2}$ Assistant Professor, \\ Department of Forensic Medicine \& Toxicology, SMVMCH, Puducherry, ${ }^{3}$ Professor, Department of Forensic \\ Medicine \& Toxicology, SMVMCH, Puducherry
}

\begin{abstract}
A medical record plays a major role for the patient and health care sector in terms of treatment and making policies on certain diseases. In any suit of negligence, this medical record will help the doctors to defend them. Many a times the complete and accurate documentation only have helped the medical fraternities from getting entangled in various consumer cases made by the patient against the doctors. Even though we have seen so many negligence cases on doctors, documentations are still incomplete in any medical record. There are studies shown that the average time spent by a doctor on a medical record is very less and the scenario is much worse when it comes to critical areas of the hospitals like casualty where the time is very precious in treating the patient and not much of importance is given for documentation. So to identify the current practice of documentation of medical records, this study was carried out to assess the documentation practice of the admission case sheets in the casualty of SMVMCH, Puducherry. An intervention was done to improve the completeness of documentation in the casualty and post-intervention analysis was also done. The results of the study showed that the percentage of documentation out of the 34 variables documented in the admission case sheets found to have significant deficiencies. But following the intervention on improving the documentation there has be a significant decrease of the deficiencies in the documentation practice on all those 34 variables.
\end{abstract}

Keywords: Medical record, Documentation, Casualty and Admission case sheet.

\section{Introduction}

In a tertiary care hospital, medical records serve as a tool to provide better clinical care and to act as a means of communication between care providers. ${ }^{1}$ Completed ocumentation of this medical record is very important, because the deficiencies in this documentation, have made the doctor's defenseless in medical negligence cases filed against them in the court. ${ }^{2}$ Casualty being the

\footnotetext{
Corresponding Author:

Dr. Ganesh Rajendiran

Assistant Professor, Department of Forensic Medicine

\& Toxicology, SMVMCH, Madagadipet, Puducherry

e-mail: fm.ganeshr@smvmch.ac.in

Tel. +917094604964
}

first place of contact, a properly documented medical record is needed proper diagnosis and treatment. ${ }^{3}$ Thus in view of a good patient care and to prevent a health care provider from negligence suits, a standardized medical record documentation is very essential. This needs to stress on the "Golden Rule" in documentation i.e. "If it isn't written down, you didn't do it." Following the Honourable Supreme Court judgement in the year 1995, stating that "doctors also come under the perview of the Consumer Protection Act, 1986 which makes the medical faternity liable under the consumer forum for deficiencies in the quality care and treatment". To safeguard the physicians from these forums, the only defensive evidence was proper documentation which is the need of the hour. ${ }^{5}$ So our study helps in identifying various deficiencies in the documentation of medical records mainly the admission case sheet in the casualty, 
followed by analysis and an interventional methodology to improve the same in the casualty, there by helping the patient to have a better care and the doctors to safeguard from litigations by having a proper documentation practice.

\section{Materials and Method}

The study was conducted at Department of Forensic Medicine,Sri Manakula Vinayagar Medical College and Hospital, Puducherry, after getting approval from the Institutional Ethics Committee approval (IEC NO97/16). It was a hospital based cross-sectional study with pre and post interventional analysis, conducted for periods of 18 months from November, 2016 to April 2018. The case sheets of patients admitted under the department of medicine, surgery and orthopaedic in casualty were used as study sample. The total sample size was calculated, by using "Open Epi software version 3.0" taking into account the improvement in the documentation of case sheets from $16.0 \%$ to $28.0 \%$ based on previous study with $95 \%$ confidential interval and $80 \%$ power, as 680 case sheets.Out of total 680 case sheets, 340 case sheets were studied during the pre-interventional period and340 case sheets during the post-interventional period using simple randomized sampling method. All case sheets of patients admitted to Casualty by the concerned departments were taken for the study.Exclusion Criteria: Out Patient case sheets attending casualty, Case sheets of patients referred to other hospitals, Case sheets of patients patient admitted to casualty by other than the Medicine, Surgery and orthopaedics department faculty. The checklist proforma for case sheets was prepared after going through the guidelines on documentation by Medical Council of India, admission case sheet format of our hospital and review of literature. The checklist proforma was scrutinized and validated by the faculty from the department of Medicine, Surgery and Orthopaedics.A total of 34 variables were identified from the admission case sheets and grouped into 6 categories for analysis purpose as follows: Category A: Sociodemographic variables (1.Patient name, 2.Address, 3.Age, 4.Sex, 5.Income, 6.Hospital number, 7.Date of patient), Category B: History variables (8.Narrated by, 9.Referred by, 10.Brought by, 11.Presenting complaints, 12.Past history, 13.Personal history, 14.Family history), Category C: Physical examination and vitals variables (15.General examination, 16.Blood pressure, 17.Pulse rate, 18.Respiratory rate, 19.Glasgow coma scale), Category D: Systemic examination variables (20.CVS examination, 21.RS examination, 22.Abdominal examination, 23.CNS examination, 24.ENT/Eye examination, 25.Oral cavity examination), Category E: Management variables (26.Provisional diagnosis, 27.Plan of management, 28.Investigation) and Category F: Doctor's variables (29.Signature of the doctor, 30.Name of the doctor, 31. Designation, 32.Registration number, 33.Date, 34.Time).340 case sheets of the patients admitted under the Department of Medicine, Surgery and Orthopaedics in emergency Department were recorded in checklist proforma before intervention. The variables in the checklist were entered in "Microsoft Excel" analysed in "Epi data analysis software version 2.2.2.186" and the deficiencies were identified.Intervention was done in the form of workshop to the faculties and post graduates of Medicine, Surgery and Orthopaedics Departments. The deficiencies found in the admission case sheets were highlightened and its importance in both improving patient care and legal implications on doctor's side were discussed. After the intervention, again the checklist proforma was filled up from 340 case sheets of patientsduring the post-interventional period. The difference between the documentation in the case sheet for pre and post interventional periods were assessed usingChi Square test. $\mathrm{P}$ value $<0.05$ was considered as statistically significant. The completeness of documentation in the case sheet was compared between pre and post interventional periods.

\section{Results}

Total of 680 admission case sheets were analyzed,out of which 340 case sheets were analyzed in the pre intervention period and 340 case sheets in the post intervention period. Out of 340 admission case sheets in the pre-interventional period, 226 case sheets were of Medicine, 66 case sheets of Surgery and 48 case sheets of Orthopedics department. In the post-intervention, 192 case sheets belonged to Medicine, 89 case sheets to Surgery and 59 case sheets to Orthopedics.

However 340 pre and 340 post interventional admission case sheets of all three departments were collectively analysed and result were compared for this study. On Comparison of "Socio-demographic variables" (Table No. 1), except the variable of documenting Hospital number, rest all variable showed a significant increase in the practice of documentation in the post-intervention period. 
Table No 1: Comparison of pre and post interventional documentation of socio demographic variables

\begin{tabular}{|c|l|c|c|c|}
\hline \multirow{2}{*}{ S.No. } & \multirow{2}{*}{ Socio demographic variables } & Pre intervention $(\mathbf{N}=\mathbf{3 4 0})$ & Post intervention (N=340) & \multirow{2}{*}{ p value } \\
\cline { 3 - 5 } & & Number (\%) & Number (\%) & $<0.001$ \\
\hline 1 & Patient name & $311(91.5)$ & $335(98.5)$ & $<0.001$ \\
\hline 2 & Address & $133(39.1)$ & $178(52.4)$ & $<0.001$ \\
\hline 3 & Age & $278(81.8)$ & $323(95.0)$ & $<0.001$ \\
\hline 4 & Sex & $277(81.5)$ & $321(94.4)$ & $<0.001$ \\
\hline 5 & Date & $219(64.4)$ & $259(76.2)$ & 0.031 \\
\hline 6 & Income of patient & $0(0.0)$ & $5(1.5)$ & 0.250 \\
\hline 7 & Hospital number & $224(65.9)$ & $238(70.0)$ & \\
\hline
\end{tabular}

Table no 2 shows the details of documentation of "History variables" in the admission case sheets during the pre- and post- intervention period and its comparison analysis. Except the variables like referred by and past history, rest all variable showed a significant increase in the practice of documentation in the post-intervention period.

Table No 2: Comparison of pre and post interventional documentation of history related variables

\begin{tabular}{|c|l|c|c|c|}
\hline \multirow{2}{*}{ S.No. } & \multirow{2}{*}{ History variables } & Pre-intervention (N=340) & Post-intervention (N=340) & \multirow{2}{*}{ p value } \\
\cline { 2 - 4 } & & Number (\%) & Number (\%) & $10(2.9)$ \\
\hline 1 & Narrated by & $3(0.9)$ & $177(52.1)$ & 0.050 \\
\hline 2 & Brought by & $143(42.1)$ & $240(70.6)$ & $<0.009$ \\
\hline 3 & Personal history & $186(54.7)$ & $150(44.1)$ & $<0.001$ \\
\hline 4 & Family history & $96(28.2)$ & $20(5.9)$ & 0.098 \\
\hline 5 & Referred by & $11(3.2)$ & $340(100.0)$ & NA \\
\hline 6 & Presenting complaints & $340(100.0)$ & $329(96.8)$ & 0.825 \\
\hline 7 & Past history & $330(97.1)$ & & 25 \\
\hline
\end{tabular}

On comparison between the documentation practice of "Physical examination and Vitals variables"it was observed from the study that variables like BP, Pulse rate and General examination were documented properly even during the pre- intervention period itself.(Table No 3 ).

Table No 3: Comparison of pre and post interventional documentation of Physical examination and Vitals variables

\begin{tabular}{|c|l|c|c|c|}
\hline \multirow{2}{*}{ S.No. } & \multirow{2}{*}{$\begin{array}{l}\text { Physical examination and } \\
\text { vitals variables }\end{array}$} & Pre intervention $(\mathbf{N}=\mathbf{3 4 0})$ & Post intervention (N=340) & \multirow{2}{*}{ p value } \\
\cline { 2 - 4 } & Number (\%) & Number (\%) & 0.394 \\
\hline 1 & Blood pressure & $316(92.9)$ & $310(91.2)$ & 0.272 \\
\hline 2 & Pulse rate & $315(92.6)$ & $332(97.6)$ & 0.806 \\
\hline 3 & General examination & $331(97.4)$ & $11(3.2)$ & 0.205 \\
\hline 5 & Coma scale & $5(1.5)$ & $23(6.8)$ & 0.328 \\
\hline
\end{tabular}

In this study, it was observed that doctors were proper in documenting the important variables like CVS, RS, CNS and Abdomen examination under the category of "Systemic examination variables". (Table No 4). 
Table No 4: Comparison of pre and post interventional systemic examination related variables

\begin{tabular}{|c|l|c|c|c|}
\hline \multirow{2}{*}{ S.No. } & \multirow{2}{*}{ System examination Variables } & Pre intervention (N=340) & Post intervention (N=340) & \multirow{2}{*}{ p value } \\
\cline { 3 - 4 } & & Number (\%) & Number (\%) & \\
\hline 1 & CVS examination & $336(98.8)$ & $336(98.8)$ & 1.000 \\
\hline 2 & RS examination & $335(98.5)$ & $336(98.8)$ & 0.737 \\
\hline 3 & Abdomen examination & $335(98.5)$ & $335(98.5)$ & 1.000 \\
\hline 4 & CNS examination & $331(97.4)$ & $329(96.8)$ & 0.650 \\
\hline 5 & ENT/Eye examination & $153(45.0)$ & $142(41.8)$ & 0.395 \\
\hline 6 & Oral cavity examination & $121(35.6)$ & $129(37.9)$ & 0.525 \\
\hline
\end{tabular}

The study has shown that doctors have documented variables like Investigation and Provisional diagnosis without any fail in the admission case sheets during the pre- and post- intervention period under the category of "Diagnosis related variables"but during pre-intervention period documentation of Plan of management wasn't done properly but later on after the intervention it was done properly. (Table No 5).

Table No 5: Comparison of pre and post interventional management relatedvariables

\begin{tabular}{|c|l|c|c|c|}
\hline \multirow{2}{*}{ S.No. } & \multirow{2}{*}{ Diagnosis related variables } & Pre intervention $(\mathbf{N}=\mathbf{3 4 0})$ & Post intervention (N=340) & \multirow{2}{*}{ p value } \\
\cline { 3 - 5 } & & Number $(\%)$ & Number (\%) & 0.008 \\
\hline 1 & Plan of management & $275(80.9)$ & $300(88.2)$ & 0.067 \\
\hline 2 & Investigation & $329(96.8)$ & $336(98.8)$ & 0.316 \\
\hline 3 & Provisional diagnosis & $337(99.1)$ & $339(99.7)$ & \multirow{2}{*}{. } \\
\hline
\end{tabular}

In this study even though the doctors were found to be only proper in documenting their signature apart from other variables under the category of "Documentation of doctor related variables"during the pre-intervention period, later on after the intervention, significant improvement was observed in all the other variables as the doctors understood the importance of documenting these variables properly. (Table No 6).

Table No 6: Comparison of pre and post interventional doctor information relatedvariables

\begin{tabular}{|c|l|c|c|c|}
\hline \multirow{2}{*}{ S.No. } & \multirow{2}{*}{$\begin{array}{l}\text { Documentation of doctor } \\
\text { variables }\end{array}$} & Pre intervention (N=340) & Post intervention (N=340) & \multirow{2}{*}{ p value } \\
\cline { 2 - 4 } & Number (\%) & Number (\%) & $<0.001$ \\
\hline 1 & Signature & $320(94.1)$ & $336(98.8)$ & $<0.001$ \\
\hline 2 & Name of doctor & $222(65.3)$ & $316(92.9)$ & $<0.001$ \\
\hline 3 & Designation & $271(79.7)$ & $298(87.6)$ & $<0.001$ \\
\hline 4 & Registration number & $176(51.8)$ & $259(76.2)$ & $<0.001$ \\
\hline 5 & Date of treatment & $219(64.4)$ & $11(3.2)$ & 0.068 \\
\hline 6 & Time & $4(1.2)$ & & 206 \\
\hline
\end{tabular}

\section{Discussion}

In our study total number of sample size was 680 case sheets which includes 340 case sheets of pre intervention period and 340 case sheets of post intervention period, taking into consideration of 34 variables from the admission case sheet, similar study was conducted by Vahedi HS et al,titled "an impact of educational intervention on medical record documentation in 
Iran" with 900 sample which including 300 medical records on pre interventional periods, 300 records on post interventional periods after 1 month and also 300 medical records on post interventional periods after 6 months and they have recorded 17 variables from all the medical record including progress sheets and admission sheets. ${ }^{6}$

In our study documentation of patient identity related variables in pre interventional period showed that the name of the patient was recorded $91.5 \%$,address $31.9 \%$, age $81.8 \%$ and sex was recorded in $81.5 \%$ where the other study of Saravi PM et al, study titled on "documentation of medical records in hospital of Mazandaran university of medical sciencein 2014" showed that the demographic findings was recorded in $95 \%$ history sheet, $90 \%$ on progress notes, $77 \%$ on admission notes and $61 \%$ of summary seats. ${ }^{7}$

Some A et al, study titled on "audit of medical record in 2010" showed that socio demographic characterstic of name,age,sex, residence, occupation,marital status and religion were available in 26 to $99 \%$ of the case sheets. This study conducted on 368 medical record on the department of medicine, surgery, obstetrics and gynaecology and paediatrics. Name of the patient were recorded in $100 \%$ on medicine and surgery departmen and totally $99.73 \%$, age of the patient were recorded $98.1 \%$, sex of the patient were recorded $91 \%$, residence were recorded in $72.6 \%$ of medical records. ${ }^{8}$

Bhanot $\mathrm{K}$ et al, tittled on"Completness in clerking: the surgical admission proforma" showed that address and age were recorded $100 \%$, date and time of admissionin and hospital number were recorded 96\% intraditional clerking before proforma induced. ${ }^{9}$ In our study documentation of personal history was recorded in $54.7 \%$ on pre interventional period. Pastor G et al, 2010 study titled "the use of a pro-forma improves the quality of the emergency medical charts of patients with acute stroke" showed that personal history was recorded $98 \%$ on medical records before inroducing pro-forma. ${ }^{10}$

Khoshbaten M EM et al, tittled an"The study of determination of re-education students and the faculty role in the improvement of medical record data files, proceeding of the $10^{\text {th }}$ medical science education" showed that the training workshop will positively effect on documentation of medical records. ${ }^{11}$ Tavakoli $\mathrm{N}$ et al, tittled an"The study of inpatient medical records on hospital educations": an interventional study showed that intervention and qualidative and quantitative analysis of medical records will improve the documentation of medical records as well as it's decrease the medical record deductions for more than $50 \% .^{12}$

Farzandipour et al, tittled an"A pilot study of the impact of an educational intervention aimed at improving medical record documentation" showed that the diagnostic accuracy was not increased in signle brief intervention. ${ }^{13}$ The study by Tinsley et $\mathrm{al}^{14}$ and other study by $\mathrm{O}$ Brien et $\mathrm{al}^{15}$ sought that the documentation could be increased by education when it was reinforces with support of faculty members with regular feedback and also training regarding their charting quality.

\section{Conclusion}

The following conclusions were made from the study i.e. awareness about the completeness of documentation on medical records was present only certain areas of documentation like documenting the patient name, presenting complaints and systemic examination, whereas other areas had not been given much importance while documenting. Explaining the medical fraternity in modes of intervention on the importance of documenting medical records in present era of evidence based medical education and increasing cases of medical negligence against doctors has been more useful by evidencing significant improvement in the documentation practice of case sheets in this study. But still there is more scope for improving the documentation process by having frequent interventions and using structured documents customized for each department in a user friendly manner.

\section{Conflict of Interest: Nil}

\section{Source of Funding: Self}

\section{References}

1. Farhan J, Jummaa S-AI, Rajhi AAI, Rayes HAI, Nasser AAI. Documentation and coding of medical records in a tertiary care centre. Annals of Saudi Medicine. 2004; 25(1):46-49.

2. Srinivasalu K, Namburi VT, Samhitha ABS. Study on documentation of medical records. Medico Legal Update. 2016; 16:154-159.

3. Hripcsak G, Sengupta S, Wilcox A, Green RA. Emergency department access to a longitudinal medical record. Journal of the American Medical Informatics Association. 2007; 14:235-238. 
4. Murphy BJ, Principles of good medical record documentation. Journal of Medical Practice Management. 2001; 16:258-60.

5. Jethani J. Medical records - It's important and relevant law. AECS illumination. 2004; 4(1):10-13.

6. Vahedi HS, Mirfakhrai M, Vahidi E, Saeedi M. Impact of an educational intervention on medical records documentation. World Journal of Emergency Medicine. 2018; 9(2):136-140.

7. Saravi BM, Asgaril Z, Siamian H, Farahabadi EB. Documentation of medical records in Hospitals of Mazandaran University of Medical Sciences in 2014: a quantitative study. Acta Informatica Medica. 2016; 24(3):202-206.

8. Some A, Outtara S, Barro S, Bambara M, Dao B. Audit of medical records. Sante (Montrouge, France). 2010; 20(3):167-171.

9. Bhanot K, Abdi J, Bamania P, Samuel M et al. Completeness in clerking: The surgical admission proforma. Annals of Medicine and Surgery. 2017; 19:1-6.

10. Pastor AG, Morcillo AC, Henriques CF, Otero DF et al. The use of porforma improves the quality of the emergency medical charts of patients with acute stroke. Neurologia. 2011; 6(9):533-539.
11. Khoshbaten M EM, Isazade KH, Ghafarufard S. Determination of re-education student and the faculty role in the improvement of medical record data files, proceedings of the $10^{\text {th }}$ medical science education. Specialty Journal of Medical Education. 2010; 6(1):23-24.

12. Tavakoli N, Jahanbakhsh M, Akbari M, Baktashian $\mathrm{M}$, et al. The student of the inpatient medical record on hospital education: an interventional study. Journal of Education and Health Promotion. 2015; $4: 38$.

13. Farzandipour MMZ, Jeddi RF, Gilsi H, Shokrizadeh AL, et al. A pilot study of the impact of an educational interventional aimed at improving medical record documentation. Journal of Royal College of Physicians of Edinburgh. 2013; 43(1):29-34.

14. Tinsely JA. An educational intervention to improve residents' inpatient charting. Academic psychiatry. 2004; 28(2):136-139.

15. O'Brien KE, Chandramohan V, Nelson DA, Fischer JR, et al. Effect of a physician directed educational campaign on performance of proper diabetic foot exam in an outpatient setting. Journal of General Internal Medicine. 2003; 18(4):258-265. 